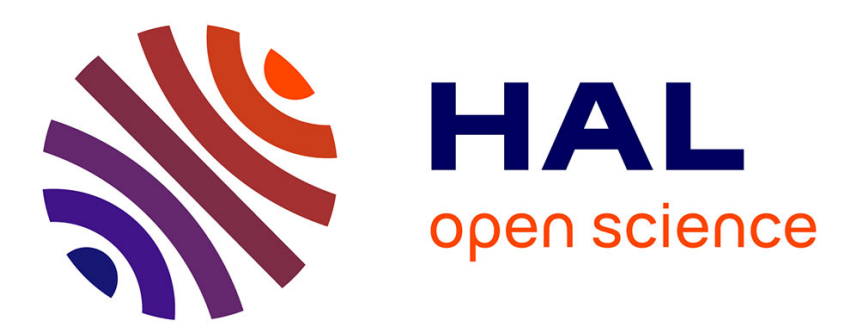

\title{
Evaluation of the influence of design in the mechanical properties of honeycomb cores used in composite panels
}

\author{
A Miranda, M Leite, L Reis, Etienne Copin, Mf Vaz, Am Deus
}

\section{To cite this version:}

A Miranda, M Leite, L Reis, Etienne Copin, Mf Vaz, et al.. Evaluation of the influence of design in the mechanical properties of honeycomb cores used in composite panels. Proceedings of the Institution of Mechanical Engineers, Part L: Journal of Materials: Design and Applications, 2021, 235 (6), pp.13251340. 10.1177/1464420720985191. hal-03113338

\section{HAL Id: hal-03113338 https://imt-mines-albi.hal.science/hal-03113338}

Submitted on 9 Mar 2021

HAL is a multi-disciplinary open access archive for the deposit and dissemination of scientific research documents, whether they are published or not. The documents may come from teaching and research institutions in France or abroad, or from public or private research centers.
L'archive ouverte pluridisciplinaire HAL, est destinée au dépôt et à la diffusion de documents scientifiques de niveau recherche, publiés ou non, émanant des établissements d'enseignement et de recherche français ou étrangers, des laboratoires publics ou privés. 


\title{
Evaluation of the influence of design in the mechanical properties of honeycomb cores used in composite panels
}

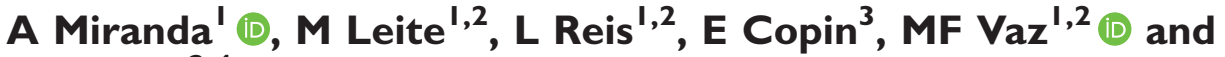 \\ AM Deus ${ }^{2,4} \mathbb{D}$
}

\begin{abstract}
The aerospace, automotive, and marine industries are heavily reliant on sandwich panels with cellular material cores. Although honeycombs with hexagonal cells are the most commonly used geometries as cores, recently there have been new alternatives in the design of lightweight structures. The present work aims to evaluate the mechanical properties of metallic and polymeric honeycomb structures, with configurations recently proposed and different in-plane orientations, produced by additive and subtractive manufacturing processes. Structures with configurations such as regular hexagonal honeycomb $(\mathrm{Hr})$, lotus $(\mathrm{Lt})$, and hexagonal honeycomb with Plateau borders $(\mathrm{Pt})$, with $0^{\circ}, 45^{\circ}$, and $90^{\circ}$ orientations were analyzed. To evaluate its properties, three-point bending tests were performed, both experimentally and by numerical modeling, by means of the finite element method. Honeycombs of two aluminum alloys and polylactic acid were fabricated. The structures produced in aluminum were obtained either by selective laser melting technology or by machining, while polylactic acid structures were obtained by material extrusion using fused filament fabrication. From the stress distribution analysis and the load-displacement curves, it was possible to evaluate the strength, stiffness, and absorbed energy of the structures. Failure modes were also analyzed for polylactic acid honeycombs. In general, a strong correlation was observed between numerical and experimental results. The results show that the stiffness and absorbed energy increase in the order, $\mathrm{Hr}, \mathrm{Pt}$, Lt, and with the orientation through the sequence, $45^{\circ}, 90^{\circ}, 0^{\circ}$. Thus, $\mathrm{Lt}$ structures with $0^{\circ}$ orientation seem to be good alternatives to the traditional honeycombs used in sandwich composite panels for those industrial applications where low weight, high stiffness, and large energy-absorbing capacity are required.
\end{abstract}

\section{Keywords}

Honeycomb cores, sandwich panels, three-point bending testing, finite element method, fused filament fabrication, selective laser melting

\section{Introduction}

Sandwich panels are widely used in the aerospace, automotive, and marine industries, as they provide lightweight, high stiffness- and high strengthto-weight ratio, excellent capability for absorbing energy, and good thermal insulation properties. ${ }^{1-6}$ The use of sandwich panels in transportation with a reduced weight of the structures promotes greater efficiency and sustainability of vehicles, with economic and environmental benefits.

A sandwich panel is composed of two face-sheets connected by a single- or multilayer low-density core. While the facesheets provide bending strength, the low-density core is responsible for the shear stiffness, energy absorption ability, and contributes to increase the flexural stiffness in the panel. ${ }^{7,8}$
The mechanical behavior of a sandwich structure depends on the material of the core and of face sheets as well as on the core topology. ${ }^{9}$ The materials of the

'IDMEC, Instituto Superior Técnico, Universidade de Lisboa, Lisboa, Portugal

${ }^{2}$ Departamento de Engenharia Mecânica, Instituto Superior Técnico, Universidade de Lisboa, Lisboa, Portugal

${ }^{3}$ Institut Clément Ader (ICA), Université de Toulouse, CNRS, IMT Mines Albi, INSA, ISAE-SUPAERO, UPS, Campus Jarlard, F-8I0I3 Albi, France

${ }^{4}$ CeFEMA, Instituto Superior Técnico, Universidade de Lisboa, Lisboa, Portugal

Corresponding author:

MF Vaz, Departamento de Engenharia Mecânica, Instituto Superior Técnico, Universidade de Lisboa, Lisbon 1049-00I, Portugal. Email: fatima.vaz@tecnico.ulisboa.pt 
core may be metallic such as, aluminum, ${ }^{1,10}$ other alloys, ${ }^{11}$ or polymers. ${ }^{12}$ The core may consist on a cellular material that can be a two-dimensional (2D) or a $3 \mathrm{D}$ cellular material. The $2 \mathrm{D}$ materials involve honeycombs, while the 3D materials comprise foams and truss/lattices. Among the cellular materials, foams exhibit a random porous structure, in contrast with honeycombs or truss/lattices that possess periodic ordered arrangements. ${ }^{2,12-16}$ Truss or lattice cores have received considerable attention because, in comparison with the honeycomb, they may exhibit superior buckling resistance, at low relative density. ${ }^{13,16,17}$

Intensive research was carried out by several researchers to study the mechanical behavior of cellular materials or of honeycomb sandwich panels under different loading conditions. ${ }^{2,10,11,13,18-23}$

The most widely studied and used core is the conventional honeycomb made by the repetition of equal hexagonal cells. ${ }^{2,24}$ However, hexagonal honeycombs show lower in-plane strength in comparison with the out-plane behavior. In order to enhance the in-plane properties of the cellular structures, as well as to increase their energy absorption, new core designs have been investigated. ${ }^{25,26}$

Several kinds of geometrical features of cellular cores have been proposed either for honeycomb type such as, square honeycomb-corrugation hybrid core, ${ }^{27}$ or for the lattice structures upon a large variety of truss cores, ${ }^{13,28,29}$ including pyramidal, ${ }^{30}$ diamond cubic, ${ }^{31,32}$ Kelvin and rhombicuboctahedron, ${ }^{33}$ Kagome, ${ }^{34,35}$ Voronoi-based arrangements, ${ }^{36}$ and other structures inspired by atomic arrangements. ${ }^{37,38}$ Recently, Araújo et al. ${ }^{7,39}$ adapted the configurations proposed by Ronan et al., ${ }^{40}$ to the core of sandwich panels.

The production of cellular solids with alternative geometries by means of the conventional manufacturing procedures would be very complicated and costly. Due to the recent developments in additive manufacturing (AM) technologies, the fabrication of cellular materials even with complex architectures, across several length scales, has been facilitated. ${ }^{26,41}$

AM encompasses a variety of technologies that create 3D objects from computer-aided design (CAD) models, in which the part is formed layer by layer, through the total or partial fusion of the material. $^{23,41,42}$

Selective laser melting (SLM) belongs to the group of AM techniques. ${ }^{43}$ The SLM process involves the complete fusion of metal powders in an inert gas chamber. A thin layer of metal powder is placed on a building platform and then it is melted due to the action of a laser beam. ${ }^{44}$ Afterwards, the building platform is lowered and a new layer of powder is deposited and subsequently melted. The laser beam can be focused across the powder layer following a computer-generated pattern, making possible to selectively melt the desired location corresponding to the cross section of the part to be manufactured. ${ }^{43}$
The main advantage of the process is its ability to produce near-net-shape metallic parts with complex geometries even at a small scale (e.g. lattice structure) directly from a 3D numerical file. The obtained final parts can have high relative densities, up to $99.9 \% .^{41}$ Still, the SLM method has the disadvantages of low production rate and the high cost associated with the preparation of the powders with a narrow particle size distribution by gas atomization. ${ }^{43}$

SLM has been utilized to produce metallic structures using several metal powders, such as stainless steel, titanium, aluminum and cobalt-chromium-molybdenum alloys, copper, nickel, and super-alloys. ${ }^{34,35,43}$

Fused filament fabrication (FFF) or material extrusion is another type of the additive procedures, which is applied to polymer part manufacturing. The FFF process uses the heating of thermoplastic polymers that are extruded by a print nozzle to form each layer. The movement of the head or nozzle is controlled by appropriate software and deposits material according to a CAD file. The material is deposited in the $X-Y$ plane of each layer, after which the nozzle shifts vertically. The part is constructed layer by layer with the required geometry. ${ }^{42,45,46}$ As the material is deposited directionally, the specimens produced exhibit an anisotropic behavior. ${ }^{47}$ Several polymers may be used in the FFF process, being the polylactic acid (PLA) amongst the most commonly used. ${ }^{48}$ PLA is a biodegradable polymer from the aliphatic polyesters group. ${ }^{49}$

In the present work, a comparative study of the mechanical properties of two configurations recently proposed for sandwich panel cores, namely lotus (Lt) and hexagonal honeycomb with Plateau borders $(\mathrm{Pt})$ arrangements, was carried out, along with the conventional regular hexagonal honeycomb (Hr). For each configuration three in-plane orientations, in particular $0^{\circ}, 45^{\circ}$, and $90^{\circ}$, were taken into account. The cellular structures were designed using a CAD program, and fabricated with two types of aluminum alloys and a polymer, PLA. Specimens from aluminum-A and PLA were processed by additive manufacturing, while samples from aluminum-S were produced by machining, which is a subtractive manufacturing process. Three-point bending (3PB) tests were conducted to investigate the strength, stiffness, and energy absorbed by the three designed core structures. A finite element (FE) analysis was carried out to determine the stress distributions in these cores. The failure mechanisms were explored on the PLA structures. Results achieved show that some of the proposed geometries may be promising alternatives to the more traditional structures.

\section{Materials and methods}

\section{Core design}

The honeycomb structures were designed using the 3D CAD program SolidWorks (SolidWorks 2018). 
The arrangements studied, namely lotus (Lt), hexagonal honeycomb with Plateau borders $(\mathrm{Pt})$, and hexagonal honeycomb $(\mathrm{Hr})$ are illustrated in the schematics of Figure 1. These core designs were previously investigated under bending and compression by Araújo et al. ${ }^{7,39}$ However, the bending behavior of these structures designed with different in-plane orientations was not addressed. In the present work, inplane rectangular samples with three different angles between the axis of the cell, $X$, and the $X_{1}$ direction of Figure 1 were studied. Three samples with angles of $0^{\circ}, 45^{\circ}$, and $90^{\circ}$, between the directions $X$ and $X_{1}$ are exemplified in Figure 2, for a lotus configuration. The structures will be denoted by the configuration type and the orientation, meaning that $\mathrm{Lt}_{-} 45$ stands for a lotus arrangement designed with an angle of $45^{\circ}$.

In cellular materials it is of utmost importance to determine the relative density, $\bar{\rho}$, which is defined as the ratio between the density of cellular material and the density of the compact material that forms the cell walls or struts. ${ }^{2}$ The relative density of a commercial hexagonal honeycomb was evaluated and the value determined was around 0.2. This enabled the authors to choose geometrical parameters that give rise to densities close to that value.
All the structures were designed with the geometrical parameters defined in Figure 1, namely $l=11.26 \mathrm{~mm}, \quad t_{0}=2.31 \mathrm{~mm}, \quad R=8.66 \mathrm{~mm}, \quad$ and $r=4.50 \mathrm{~mm}$. The radius of the plateau border was set as $r=0.4 \times l$ in the Pt configuration. The relative density of each structure depends on the geometrical parameters ${ }^{40}$ defined in Figure 1, and is in the range $0.22-0.29$ for the three different geometries. As the structures are different it is not possible to obtain the same value of relative density while keeping the geometrical parameters fixed.

The specimens were made with the same number of cells and dimensions around $L \times 67.6 \times 10 \mathrm{~mm}$, where $L$ is the length of the sample. As will be detailed in next sections, three different materials were used in the manufacturing of the samples, aluminum-A, aluminum-S, and polylactic acid, PLA. Samples of aluminum-A were fabricated by SLM. Due to the restrictions in size associated to this equipment, the length, $L$, of those samples had to be reduced. Overall, the length $L$ was set to $117 \mathrm{~mm}$ for aluminum-A and $L=136.5 \mathrm{~mm}$ for the aluminum-S and PLA. Aluminum-A honeycombs due to size reduction are designated by an asterisk following the nomenclature adopted previously (for example,

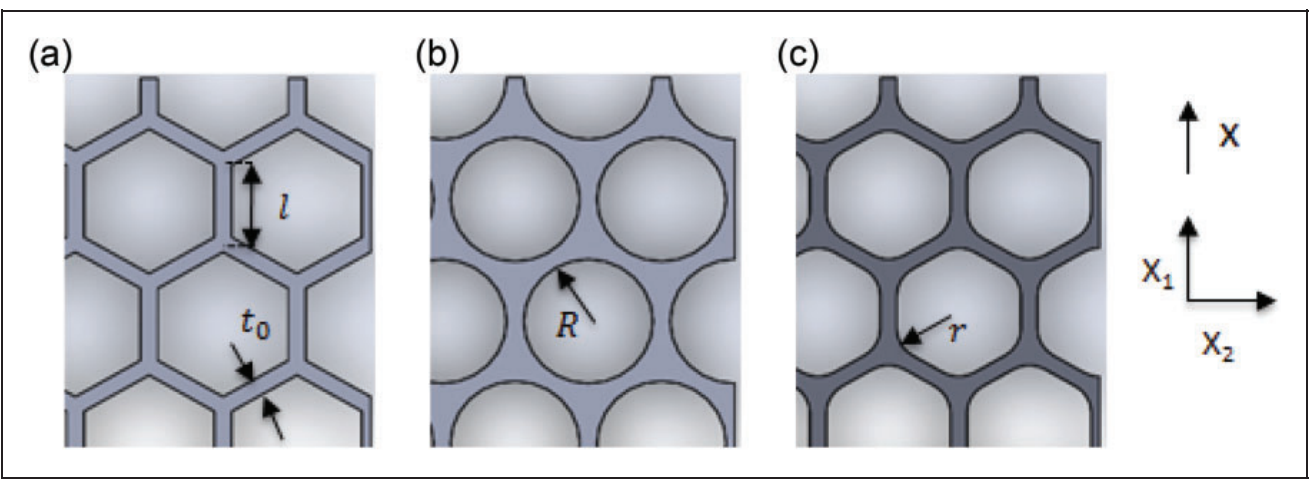

Figure I. Schematics of cellular configurations: (a) regular hexagonal honeycomb (Hr), (b) lotus (Lt), and (c) hexagonal honeycomb with plateau borders $(\mathrm{Pt})$. The borders have radius $r=0.4 \times I$ (and relative density $\bar{\rho} \approx 0.2$ ). The direction $X_{3}$ is perpendicular to the $X_{1}-X_{2}$ plane.

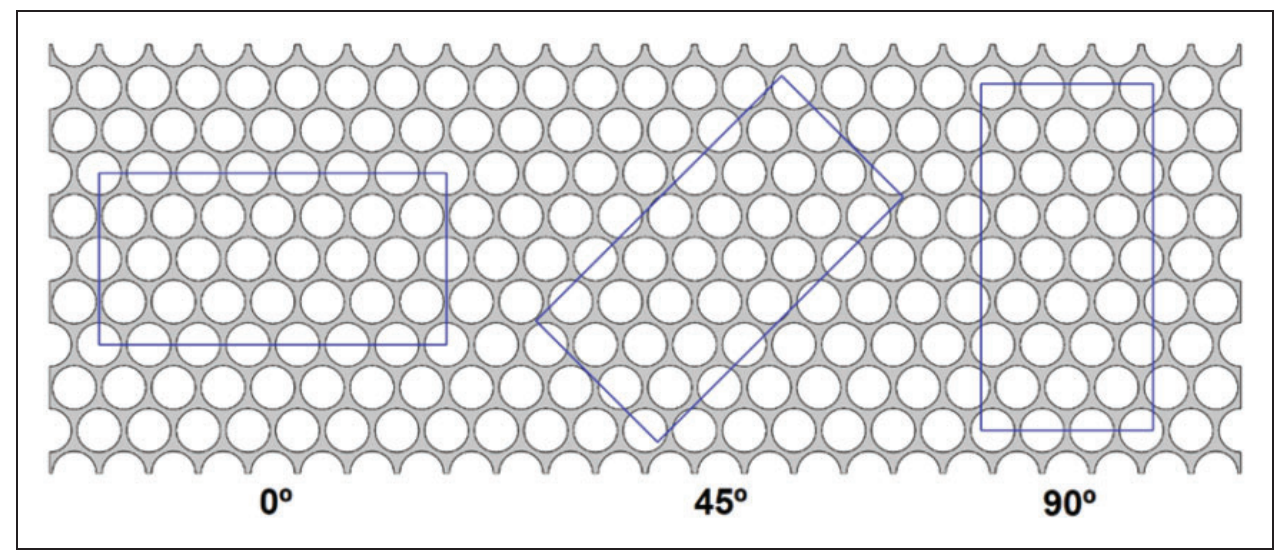

Figure 2. Example of the different in-plane orientation samples, $0^{\circ}, 45^{\circ}$, and $90^{\circ}$, for a lotus configuration. 
$\left.\mathrm{Hr} 0^{*}\right)$. Nine distinct structures resulting from the combination of three different configurations with three different angles were designed.

\section{Materials}

As previously stated, three materials were used in the fabrication of the honeycomb structures, namely two aluminum alloys and a polymer, PLA.

Aluminum-A is an AlSi7Mg0.6 cast alloy (DIN EN 1706), acquired from SLM Solutions Group AG Lübeck, Germany, allows the fabrication of the samples by SLM.

The so-called aluminum-S is the aluminum alloy 7075-T6, purchased from Thyssenkrupp Materials NA, Germany. It allowed obtaining samples by machining. The data of the physical and mechanical properties of both aluminum alloys are featured in Table 1, according to the information provided by the suppliers. Table 1 shows the values of the density $\rho$, Young's modulus $E$, Poisson's ratio $v$, yield strength $\sigma_{Y}$, ultimate strength $\sigma_{U}$, and ultimate strain $\epsilon_{U}$.

The PLA was purchased from the company ESUN (esun3d.net). Due to some uncertainty about the mechanical properties of PLA, tensile tests were carried out on samples manufactured with two raster angles, $\alpha$, with the values $0^{\circ}$ and $45^{\circ}$. The values of the modulus $E$, yield strength $\sigma_{Y}$, ultimate strength $\sigma_{U}$, and ultimate strain $\epsilon_{U}$, shown in Table 1, were determined following the procedure used by Fernandes et al. ${ }^{50}$ The density and the Poisson's ratio were obtained from the literature. ${ }^{49}$

\section{Manufacturing}

The three groups of samples were fabricated by using two additive manufacturing techniques (SLM and material extrusion) and a conventional procedure (machining).

The honeycomb structures made of aluminum-A were fabricated by selective laser melting (SLM) process, on an SLM Solutions 125HL device (SLM Solutions Group AG Lübeck, Germany) at the Institut Clément Ader (ICA), IMT Mines Albi, France. The metallic powders had diameter ranging from 20 to $63 \mu \mathrm{m}$. The powders were melted through laser irradiation in order to obtain the cellular core, through a layer by layer procedure. The chamber was filled with Argon ((partial pressure of oxygen kept below 0.1 at. \%) to limit material oxidation.
The building platform was held at $150^{\circ} \mathrm{C}$ during the whole process to reduce thermal stresses. A rotation angle of the scanning directions of $67^{\circ}$ between consecutive layers was used. The process parameters are listed in Table 2.

Cellular cores of the aluminum-S alloy were machined on a three-axis CNC vertical milling device model VF-2SS (Haas Automation, Inc.) at the company Viagop, Lisbon, Portugal.

The PLA structures were fabricated using material extrusion in an Ultimaker 3 device (Ultimaker B.V., Utrecht, The Netherlands). The structures designed in CAD software were exported as STL files and were processed by the software CURA from Ultimaker, prior to printing. The samples were produced with an extrusion temperature of $210^{\circ} \mathrm{C}$, a build plate temperature of $60^{\circ} \mathrm{C}$ and a layer thickness of $0.1 \mathrm{~mm}$. The printing speed was $80 \mathrm{~mm} / \mathrm{s}$ and the infill density was set to $100 \%$. Three samples for each arrangement were fabricated.

All the nine designed structures were produced by material extrusion in PLA. However, aluminum-A samples were only fabricated for samples $\mathrm{Hr}_{-} 0^{*}$, Lt_0*, and Pt_0*. Also specimens fabricated with aluminum-S were restricted to the two arrangements, lotus and hexagonal honeycomb with Plateau borders, as the available equipment did not enable to perform hexagonal honeycomb configurations. Examples of the three types of samples produced through the three manufacturing procedures are given in Figure 3.

\section{Finite element modeling}

The FE analysis of the 3PB test was conducted using Abaqus software, version 6.19 (Dassault Systemes S. A.). The honeycomb core was placed between two lower fixed supports and an upper support (Figure 4(a)) that moves until a maximum displacement, being of $2.5 \mathrm{~mm}$ for aluminum and of $8 \mathrm{~mm}$ for

Table 2. SLM process parameters.

\begin{tabular}{ll}
\hline Parameter & Value \\
\hline Laser power & $350 \mathrm{~W}$ \\
Laser focus & $70-100 \mu \mathrm{m}$ \\
Scanning speed & $1150 \mathrm{~mm} / \mathrm{s}$ \\
Layer thickness & $50 \mu \mathrm{m}$ \\
Hatch space & $170 \mu \mathrm{m}$ \\
Angle increment & $67^{\circ}$ \\
\hline
\end{tabular}

Table I. Physical and mechanical properties of the aluminum-A, aluminum-S, and PLA.

\begin{tabular}{lllllll}
\hline Material & $\rho\left(\mathrm{g} / \mathrm{cm}^{3}\right)$ & $E(\mathrm{GPa})$ & $\nu$ & $\sigma_{Y}(\mathrm{MPa})$ & $\sigma_{U}(\mathrm{MPa})$ & $\epsilon_{U}$ \\
\hline Aluminum-A & 2.68 & $59 \pm 21$ & 0.33 & $211 \pm 18$ & $375 \pm 17$ & $0.08 \pm 0.02$ \\
Aluminum-S & 2.80 & 71.7 & 0.33 & 503 & 572 & 0.11 \\
PLA $\left(\alpha=0^{\circ}\right)$ & 1.25 & $1.27 \pm 0.023$ & 0.36 & $25.2 \pm 0.2$ & $48.7 \pm 2.0$ & $0.048 \pm 0.004$ \\
PLA $\left(\alpha=45^{\circ}\right)$ & 1.25 & $1.24 \pm 0.014$ & 0.36 & $25.3 \pm 0.1$ & $52.6 \pm 0.6$ & $0.055 \pm 0.001$ \\
\hline
\end{tabular}




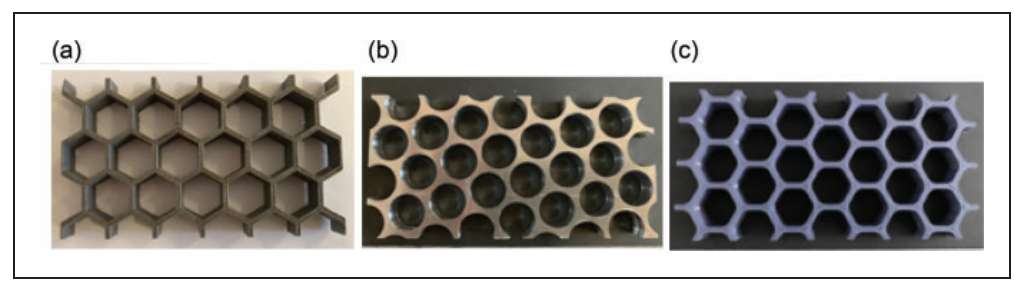

Figure 3. Example of specimens of different materials obtained by different procedures: (a) aluminum-A (SLM), (b) aluminum-S (machining), (c) PLA (material extrusion).

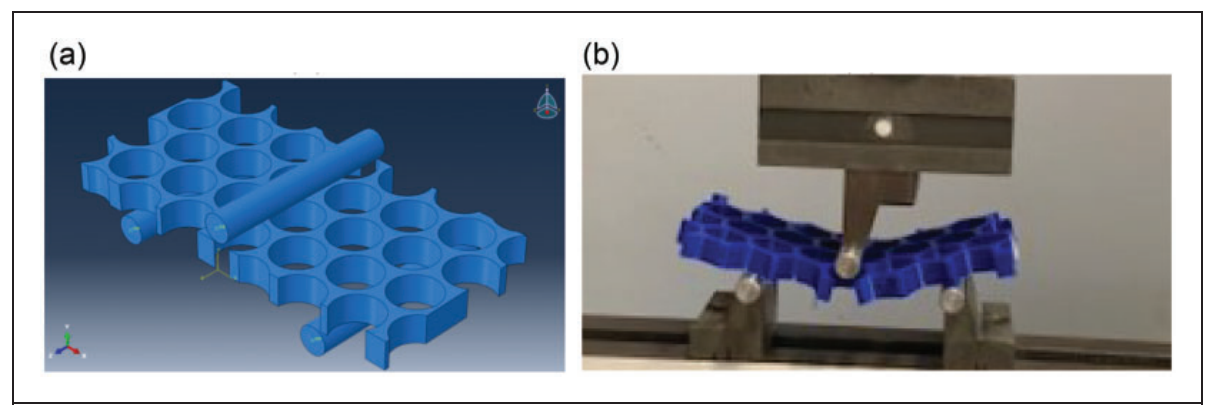

Figure 4. Three-point bending (3PB) of PLA samples: (a) numerical model and (b) experimental setup.

PLA honeycombs. The support span was taken as $80 \mathrm{~mm}$. The lower supports have all degrees of freedom fixed. Contact was considered with a tangential behavior and a friction coefficient of 0.20 .

The supports of the $3 \mathrm{~PB}$ tests were modeled as a discrete rigid material having a radius of $5.0 \mathrm{~mm}$. Honeycombs were modeled with elastic-plastic behavior, with linear and isotropic hardening. The properties of the three materials used, such as density $\rho$, Young's modulus E, Poisson's ratio $v$, yield strength $\sigma_{Y}$, ultimate strength $\sigma_{U}$, and ultimate strain $\in_{\mathrm{U}}$, are indicated in Table 1 . As the Young's modulus for aluminum-A is given, by the supplier, as $E=59 \pm 21 \mathrm{GPa}$, which is a wide range, simulations were performed with three values of $E$, namely $E=38,59$, and $80 \mathrm{GPa}$.

For PLA honeycombs with $0^{\circ}$ and $90^{\circ}$ orientation, the properties used were the ones obtained under tensile tests for $\alpha=0^{\circ}$, while for $45^{\circ}$ orientation honeycombs, the properties achieved for $\alpha=45^{\circ}$ were considered.

For honeycombs with $0^{\circ}$ and $90^{\circ}$ orientations, the symmetry boundary condition according to the $x$-axis of Figure 4(a), enables to consider only half of the sample, allowing to reduce computational time.

The meshes of the supports and honeycombs were made automatically by defining the approximate global size. The support meshes are formed by R3D4 (a 4-node 3D bilinear rigid quadrilateral) and R3D3 (a three-node 3D rigid triangular facet) elements, whereas honeycomb meshes have only C3D8R (an eight-node linear brick, reduced integration, hourglass control) elements.

From the simulations, it was possible to obtain the load-displacement data. The load was determined by the force applied by the upper support on the honeycombs, while the displacement was taken from the nodes belonging to elements underneath the upper roller.

Several parameters may be extracted from the load-displacement curves. The initial slope of the linear region of the curves enables to evaluate stiffness, $K$. The area under the curve allows evaluating the energy absorbed, $E_{\mathrm{a}}$, until maximum load. From the von Mises stress distribution, it was possible to determine the maximum stress $\sigma_{\max }$, which is a measure of the strength of each tested configuration.

A von Mises stress convergence analysis was performed on the PLA configurations $\mathrm{Hr}_{-} 0$, Lt_0, and Pt_0 in the elastic regime, using $E=1.3 \mathrm{GPa}$ and $v=0.36$. Note that due to symmetry in the $x$ direction of Figure 4(a)), only half of the honeycombs were simulated in this analysis. The point chosen for analysis has the same coordinates in all models and is in the plane of symmetry used at the bottom of the structure, to avoid being in the contact zone. Although convergence should be formally analyzed for all models and orientations, in this paper it was assumed that the results obtained also applied to the remaining orientations, since convergence is mainly related to the type and size of elements.

The convergence criterion was taken as less than $2 \%$ changes in the highest von Mises stress. Figure 5 illustrates the variation of the von Mises stress as a function of the number of nodes for the arrangements Lt_0, Pt_0, and Hr_0. From this analysis, the element size was set as $0.6 \mathrm{~mm}$ for the arrangements $\mathrm{Hr}$ and $\mathrm{Pt}$, while for the Lt configuration a global size of $0.7 \mathrm{~mm}$ was used. The element size chosen corresponds to a number of elements in configurations 


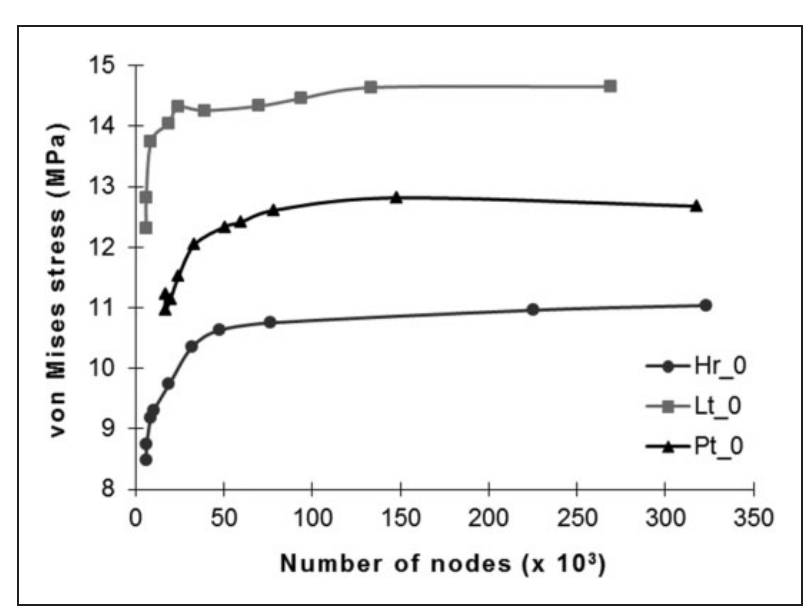

Figure 5. Convergence analysis: evolution of the von Mises stress in function of number of nodes for the arrangements Hr_0, Lt_0, and Pt_0.

Hr_0, Lt_0, and Pt_0, of 58,786, 76,228, and 46,116, respectively.

\section{Experimental tests}

The 3PB tests were conducted following ASTM D790-17 (standard test methods for flexural properties of unreinforced and reinforced plastics and electrical insulating materials). Tests were performed on an Instron 3369 universal testing device with a $50 \mathrm{kN}$ load cell. Figure 4(b) shows the experimental set up for $3 \mathrm{~PB}$ tests. The span length was $80 \mathrm{~mm}$.

A cross-head speed of $0.5 \mathrm{~mm} / \mathrm{min}$ was used for testing the aluminum models, while a speed of $2.5 \mathrm{~mm} / \mathrm{min}$ was used for PLA structures. In the tests of aluminum-A models, the final displacement of the upper support, $d l$, was taken as $1 \mathrm{~mm}$, while for aluminum-S samples, tests were performed until $d l=1.5 \mathrm{~mm}$. The bending tests of PLA specimens were conducted until failure of the structures.

Bluehill data acquisition software was used to obtain the experimental load-displacement curves, from which the stiffness, $K$, and the energy, $E_{\mathrm{a}}$, were determined. The failure modes of PLA samples were further explored.

\section{Results}

The results of the three groups of material samples will be evaluated separately, for each type of material.

\section{Specimens of aluminum- $A$}

Figure 6 displays the load-displacement curves for aluminum-A configurations $\mathrm{Hr}_{-} 0^{*}, \mathrm{Lt}_{-} 0^{*}$, and Pt_ $0^{*}$. Both numerical and experimental curves are shown. As mentioned, simulations were undertaken with three different Young's modulus, $E=38 \mathrm{GPa}$, $E=59 \mathrm{GPa}$, and $E=80 \mathrm{GPa}$. Figure 6(a), (c), and (e) reveals the simulation results with these three Young's modulus for each configuration, while
Figure 6(b), (d), and (f) exhibit the comparison of the curves obtained by experiments and simulations. The numerical analysis was performed until a predefined displacement of $2.5 \mathrm{~mm}$, but as the experiments were only accomplished until $d l=1.0 \mathrm{~mm}$, the numerical curves of Figure 6(b), (d), and (f) are presented until $d l=1.0 \mathrm{~mm}$ as well.

FE analysis reveals that the shape of the numerical curves has the same trend with the increase in $E$, apart differences in values, for the three arrangements. As $E$ increases the load-displacement curves show more clearly two different slopes. For a fixed $E$ and $d l$, the configuration that achieves higher loads is Lt_0*, followed by Pt_0* and Hr_0* (Figure 6). A good fitting was found between experimental curves and numerical data obtained with $E=38 \mathrm{GPa}$, for the arrangements $\mathrm{Hr}_{-} 0^{*}$ and Lt_ $0^{*}$. However, in the case of Pt_0*, the experimental results are not so close to the FE data obtained with $E=38 \mathrm{GPa}$. In this case, simulations conducted with $E=30 \mathrm{GPa}$, exhibit a better fitting.

Figure 7 shows the von Mises stress distributions after $3 \mathrm{~PB}$ tests for the configurations $\mathrm{Hr}_{-} 0^{*}$, Lt $0^{*}$, and Pt_ $0^{*}$ made of aluminum-A, under two final displacements, $\quad d l=1.0 \mathrm{~mm}$ and $d l=2.5 \mathrm{~mm}$. As expected, as the displacement increases, the areas that attain plastic deformation are enlarged. The maximum stress is achieved, for arrangements $\mathrm{Hr} \_0^{*}$ at the triple junctions, while for the Pt_0* occurs close to the Plateau borders and in the Lt_0* is attained at the lowest thickness walls, i.e. at the middle of the strut. The main localization of deformation was found to occur at the upper and lower zones of the structure, at the middle of the plate, where the upper support contacts the cellular structure.

Table 3 shows the parameters, maximum von Mises stress $\sigma_{\max }$, stiffness $K$, and absorbed energy $E_{\mathrm{a}}$, until $d l=1.0 \mathrm{~mm}$, for bending tests carried out by $\mathrm{FE}$ analysis and with experimental testing, of aluminum-A. Simulations were undertaken with $E=38 \mathrm{GPa}$. The parameters are scaled to the relative density, as in previous works. ${ }^{7,39}$ Among the three structures, the Lt_ ${ }^{*}$ configuration attains the highest values of stiffness and absorbed energy. However, the structure Hr_0* of aluminum-A sustains the highest maximum von Mises stress, i.e. possesses the highest strength, but shows the lowest stiffness and absorbed energy in terms of numerical results. FE analysis shows that Pt_0* has superior $K / \bar{\rho}$ and $E_{\mathrm{a}} / \bar{\rho}$ than the structure $\mathrm{Hr} \_0$. However, the same is not verified within the experimental tests. Although the values of Table 3 of experimental data and FE analysis are in the same order of magnitude, the differences among them are in the range of $6-30 \%$.

\section{Specimens of aluminum-S}

Figure 8 exhibits the load-displacement curves obtained under experiments and simulations of 

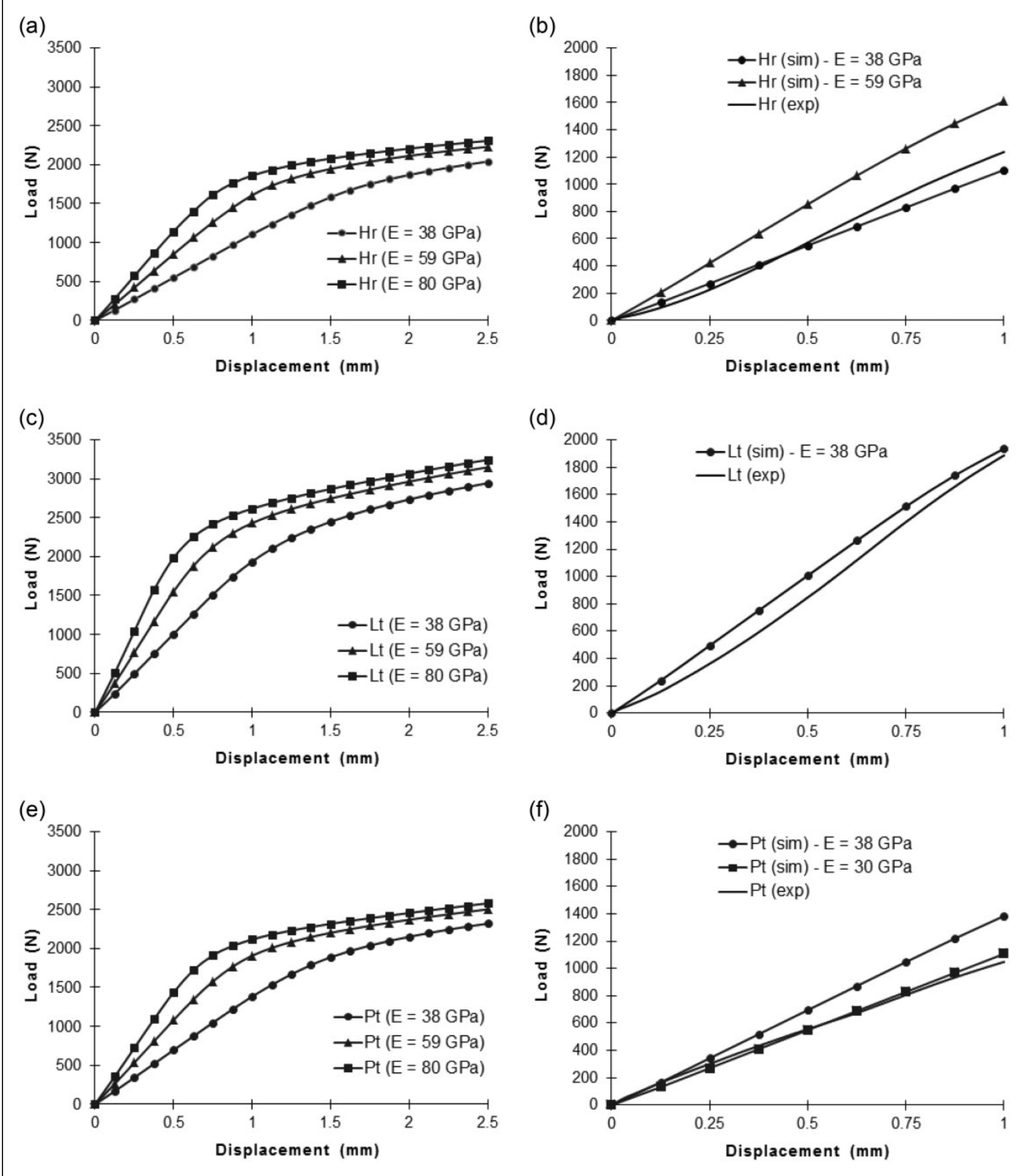

Figure 6. Load-displacement curves for aluminum-A honeycombs: (a, b) Hr_0*, (c, d) Lt_ $0^{*},(e, f) P t \_0^{*}$. Numerical curves (a), (c), (e) up to a displacement $d l=2.5 \mathrm{~mm}$, with three Young's modulus 38, 59, and $80 \mathrm{GPa}$; (b), (d), (f) numerical and experimental curves until a displacement $d l=I \mathrm{~mm}$.

aluminum-S arrangements. The effect of the in-plane orientation was evaluated for the arrangements $\mathrm{Lt}$ and Pt. For the three orientations studied, the load is always higher for the lotus arrangement in comparison with hexagonal honeycomb with Plateau borders, at a fixed displacement. From Figure 8, one may observe that, for the same displacement, structures with $0^{\circ}$ angle of orientation support the highest load, while the lowest load is attained by structures with $45^{\circ}$ angles.

Figure 9 shows the von Mises stress distribution obtained in the simulations of 3PB tests carried out until a final displacement of $1.5 \mathrm{~mm}$, with aluminum$\mathrm{S}$ structures. The areas that attain plastic deformation are found to depend on the geometry and on the inplane orientation. The areas of plastic deformation 


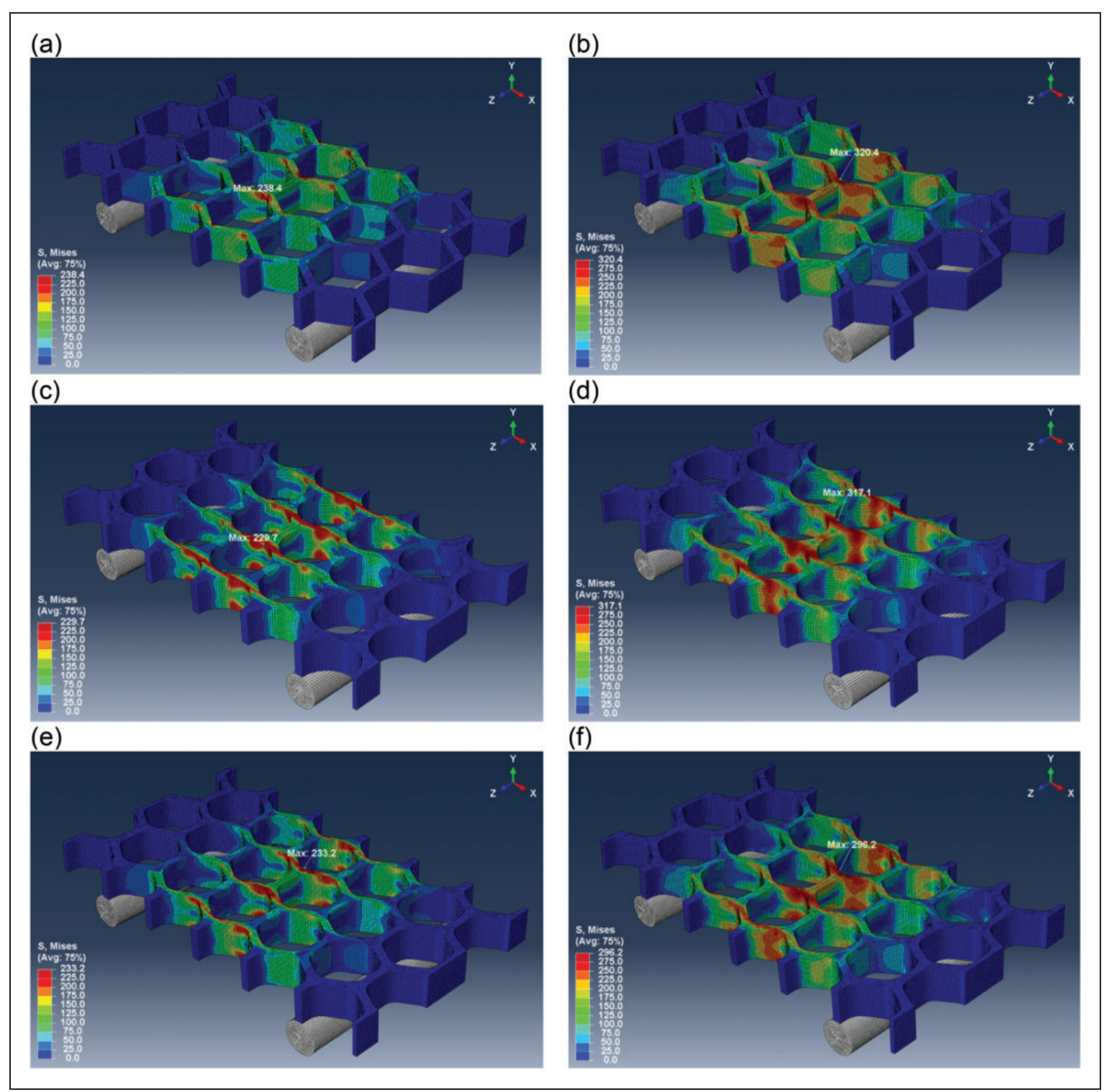

Figure 7. Finite element analysis of stresses (von Mises stress (MPa)), after bending tests of honeycomb, lotus, and plateau configurations made of aluminum-A, with $E=38 \mathrm{GPa}$ and two displacements. Configurations (a)-(b) Hr_0*, (c)-(d) Lt_0*, (e)-(f) Pt_0*. Final displacement $d l=1 \mathrm{~mm}(\mathrm{a}),(\mathrm{c}),(\mathrm{e})$; and $d \mathrm{l}=2.5 \mathrm{~mm}(\mathrm{~b})$, (d), (f).

Table 3. FE and experimental results for bending tests of aluminum-A samples: maximum von Mises stress $\sigma_{\max }$, stiffness $K$, and absorbed energy $E_{a}$, (scaled with the relative density, $\bar{\rho}$ ) until $d l=1.0 \mathrm{~mm}$. Simulations were undertaken with $E=38 \mathrm{GPa}$.

\begin{tabular}{|c|c|c|c|c|c|c|}
\hline \multirow[b]{2}{*}{ Model } & \multirow[b]{2}{*}{$\bar{\rho}$} & \multicolumn{3}{|l|}{ Finite elements } & \multicolumn{2}{|l|}{ Experimental } \\
\hline & & $\bar{\sigma}_{\max } / \bar{\rho}(\mathrm{MPa})$ & $K / \bar{\rho}(\mathrm{N} / \mathrm{mm})$ & $E_{a} / \bar{\rho}(J)$ & $K / \bar{\rho}(\mathrm{N} / \mathrm{mm})$ & $E_{a} / \bar{\rho}(\mathrm{J})$ \\
\hline $\mathrm{Hr} \_0 *$ & 0.223 & $1.07 \times 10^{3}$ & $4.98 \times 10^{3}$ & 2.47 & $6.64 \times 10^{3}$ & 2.62 \\
\hline Lt_o* & 0.285 & $8.07 \times 10^{2}$ & $7.12 \times 10^{3}$ & 3.50 & $7.80 \times 10^{3}$ & 3.11 \\
\hline Pt_0* & 0.243 & $9.61 \times 10^{2}$ & $5.77 \times 10^{3}$ & 2.86 & $4.13 \times 10^{3}$ & 2.27 \\
\hline
\end{tabular}

decrease in the sequence of angles $0^{\circ}, 45^{\circ}$, and $90^{\circ}$ (Figure 9). For the three structures Lt_0, Lt_45, and Lt_90, the highest values of stress are attained at the middle of the cell wall or strut of the structure. However, for Pt structures there are distinct location for different angle orientation, showing samples Pt_0 the maximum values of stress close to the plateau border, while structures $\mathrm{Pt} \_45$ and $\mathrm{Pt} \_90$ achieved high stresses at the middle of the struts.

The numerical and experimental results of $3 \mathrm{~PB}$ of the aluminum-S specimens are exhibited in Table 4 with the ratio of parameters $\sigma_{\max } / \bar{\rho} K / \bar{\rho}$, and $E_{\mathrm{a}} / \bar{\rho}$, scaled to the relative density. It may be noted that, for the three different angles, lotus structures possess 


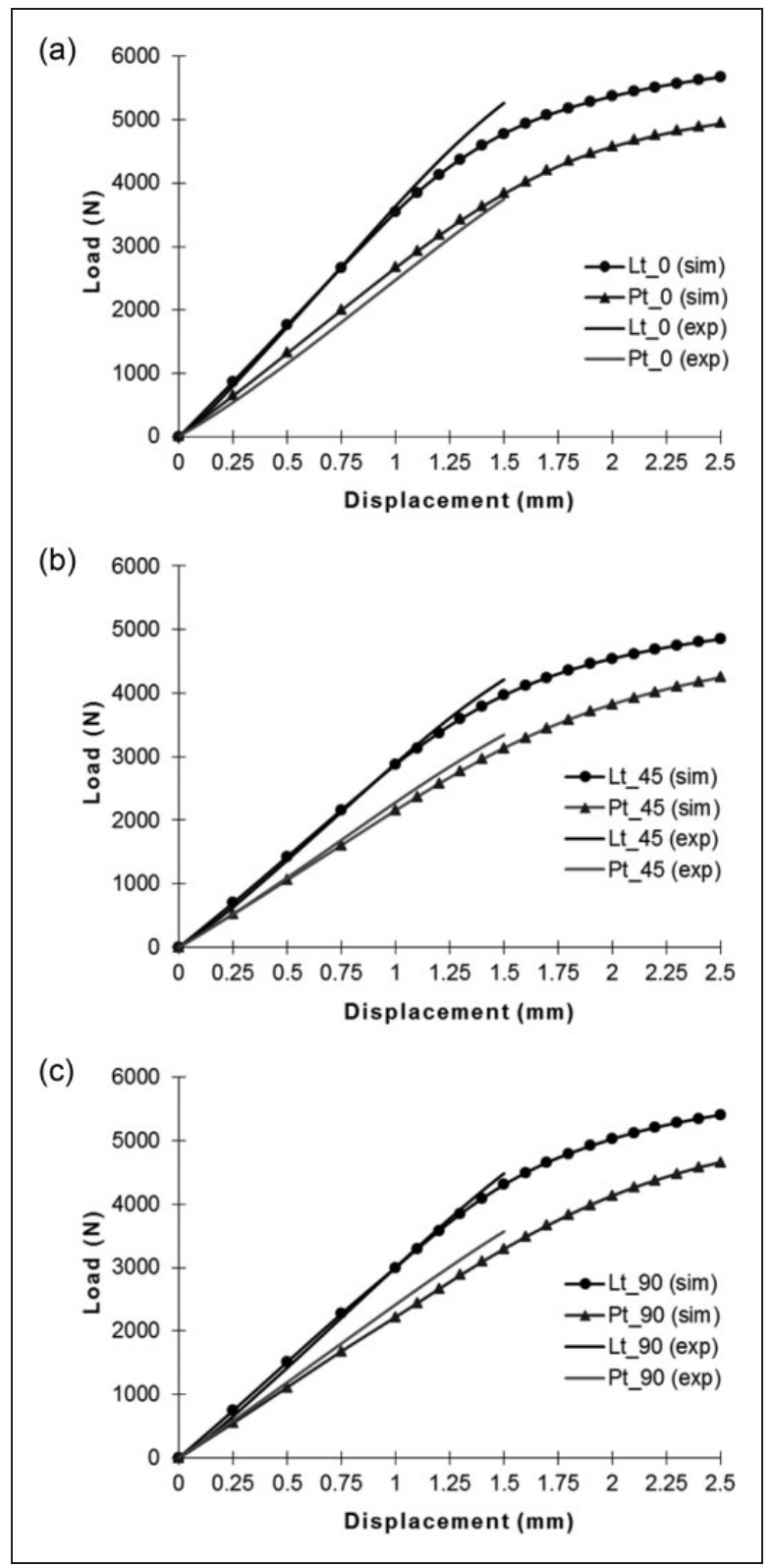

Figure 8. Numerical and experimental load-displacement curves for aluminum-S configurations $\mathrm{Lt}$ and $\mathrm{Pt}$ with orientations (a) $0^{\circ}$, (b) $45^{\circ}$, (c) $90^{\circ}$.

higher stiffness and absorbed energy in comparison with the hexagonal honeycomb with Plateau borders, either in experiment or in simulation results. On the other hand, all the Pt structures attain higher strength than the Lt specimens evaluated by the maximum von Mises stress.

For both Lt and Pt structures, the values of $K / \bar{\rho}$ and $E_{\mathrm{a}} / \bar{\rho}$ increase in the sequence of $45^{\circ}, 90^{\circ}$, and $0^{\circ}$ angle of orientation, which means that a $0^{\circ}$ sample provides the highest values of stiffness and absorbed energy. The values of the maximum von Mises stress are higher for the $90^{\circ}$ orientation in comparison with the angles $0^{\circ}$ and $45^{\circ}$, for the structures Lt and Pt. Samples Pt_0 and Pt_45 have almost the same values of $\sigma_{\max } / \bar{\rho}$, which is also verified for samples Lt_0 and Lt_45.
The differences of the experimental and numerical values (Table 4) are in an interval of $0.9-9 \%$, which is lower than the case of aluminum-A samples.

\section{Specimens of PLA}

As mentioned previously, the PLA samples were manufactured for the nine possible combinations of the three configurations and three angles of orientation. Figure 10 shows the mechanical response of the structures subjected to $3 \mathrm{~PB}$ numerical and experimental tests. The FE simulation curves show values much lower than the ones obtained with the experiments, although qualitatively they exhibit the same trends. However, experimental load-displacement curves show an elastic-plastic behavior, which differs from the one corresponding to FE curves.

For a given configuration and the same displacement, structures with $0^{\circ}$ orientation are the ones bearing higher load, while the lowest load is supported by structures with $45^{\circ}$ orientation. Keeping the orientation angle fixed, the highest load values are achieved in the Lt structures, while the $\mathrm{Hr}$ structures attain the lowest values of load.

The von Mises stress distribution of PLA samples is presented in Figure 11, after a 3PB test with a predefined displacement of $2.5 \mathrm{~mm}$. In the structures $\mathrm{Lt}$ and $\mathrm{Pt}$ the deformation is localized at the same zones as in aluminum-S samples. For example for the lotus structures the highest values of stress can be found at a thinner cell wall of the structure. In the Pt structures, the specimens Pt_0 achieve maximum stress close to the plateau border, but structures Pt 445 and Pt 90 reached high stresses at the cell walls of lower thickness. The localization of deformation in $\mathrm{Hr}$ samples depend on the orientation angle, with structure $\mathrm{Hr}_{-} 0$ exhibiting high stress values at the triple joints, while $\mathrm{Hr}$-45 shows values of stresses maximum at the struts making angles of $45^{\circ}$ with axis $X$ (Figure 1), or struts parallel to axis $X$, which is the case of Hr.90.

Table 5 presents the FE and experimental results for bending tests of PLA samples, in particular, maximum von Mises stress $\sigma_{\max }$, stiffness $K$, and absorbed energy $E_{\mathrm{a}}$, scaled to the relative density, for a displacement $d l=2.5 \mathrm{~mm}$. The lotus structure, $\mathrm{Lt}$, displays the highest stiffness and absorbed energy among the three structures, with larger values for experiments and numerical tests, for the three orientations. The honeycomb with Plateau borders, Pt, also present values of $K / \bar{\rho}$ and $E_{\mathrm{a}} / \bar{\rho}$ larger than the hexagonal honeycomb. There is a tendency for the structure $\mathrm{Hr}$ to have higher strength than the structures Lt and Pt, with the exception of the sample $\mathrm{Hr} 45$.

For the three structures, the stiffness evaluated by $K / \bar{\rho}$ and the absorbed energy $E_{\mathrm{a}} / \bar{\rho}$ are higher at the angle $0^{\circ}$, followed by $90^{\circ}$ and $45^{\circ}$, with only an exception for $\mathrm{Hr}_{-} 45$ and $\mathrm{Hr}_{-} 90$ that present almost the 


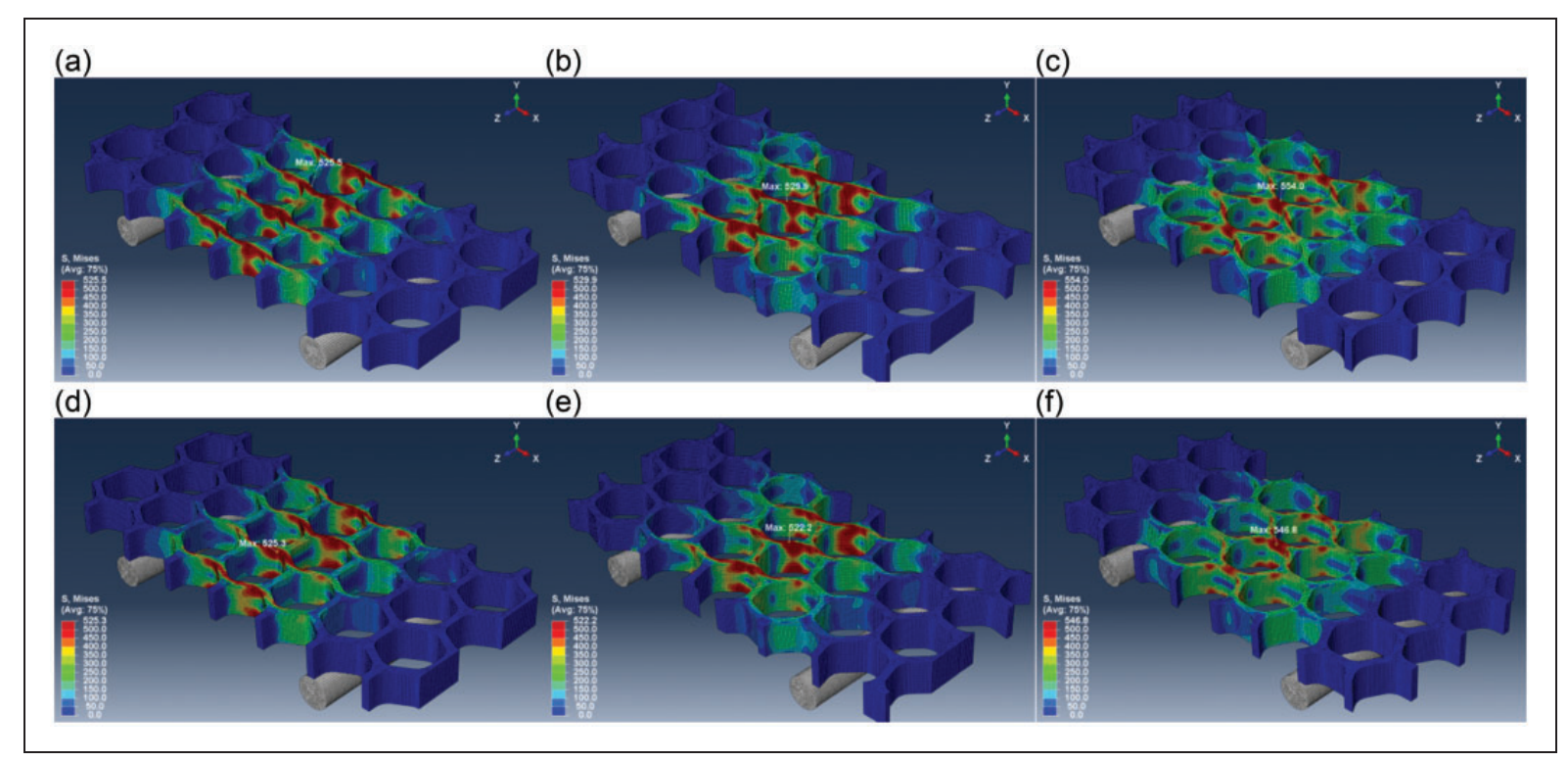

Figure 9. Finite element analysis of stresses (von Mises stress (MPa)), after bending tests of honeycomb, lotus, and plateau configurations made of aluminum-S for a displacement of $1.5 \mathrm{~mm}$. (a) Lt_0, (b) Lt_45, (c) Lt_90, (d) Pt_0, (e) Pt_45, (f) Pt_90.

Table 4. FE and experimental results for bending tests of aluminum- $S$ samples: maximum von Mises stress $\sigma_{\max }$, stiffness $K$, and absorbed energy $E_{a}$, (scaled with the relative density, $\bar{\rho}$ ) until $d l=1.5 \mathrm{~mm}$.

\begin{tabular}{|c|c|c|c|c|c|c|}
\hline \multirow[b]{2}{*}{ Model } & \multirow[b]{2}{*}{$\bar{\rho}$} & \multicolumn{3}{|l|}{ Finite elements } & \multicolumn{2}{|l|}{ Experimental } \\
\hline & & $\bar{\sigma}_{\max } / \bar{\rho}(\mathrm{MPa})$ & $K / \bar{\rho}(\mathrm{N} / \mathrm{mm})$ & $E_{a} / \bar{\rho}(J)$ & $\mathrm{K} / \bar{\rho}(\mathrm{N} / \mathrm{mm})$ & $E_{a} / \bar{\rho}(J)$ \\
\hline Lt_0 & 0.285 & $1.85 \times 10^{3}$ & $1.25 \times 10^{4}$ & 13.6 & $1.33 \times 10^{4}$ & 14.1 \\
\hline Lt_45 & 0.286 & $1.86 \times 10^{3}$ & $1.01 \times 10^{4}$ & II.I & $1.07 \times 10^{4}$ & 11.2 \\
\hline Lt_90 & 0.284 & $1.95 \times 10^{3}$ & $1.07 \times 10^{4}$ & 11.8 & $1.12 \times 10^{4}$ & 11.7 \\
\hline Pt_0 & 0.243 & $2.16 \times 10^{3}$ & $1.10 \times 10^{4}$ & 12.2 & $1.10 \times 10^{4}$ & 11.3 \\
\hline Pt_45 & 0.244 & $2.14 \times 10^{3}$ & $8.85 \times 10^{3}$ & 9.8 & $9.73 \times 10^{3}$ & 9.3 \\
\hline Pt_90 & 0.242 & $2.26 \times 10^{3}$ & $9.16 \times 10^{3}$ & 10.3 & $1.01 \times 10^{4}$ & 11.2 \\
\hline
\end{tabular}

same values obtained in experiments. The values of the maximum von Mises stress are not much distinct for the structures oriented with angles of $0^{\circ}$ and $90^{\circ}$, but present lower values for the angle orientation of $45^{\circ}$. This means that orientations of $45^{\circ}$ have the lowest strength, for the three structures studied.

\section{Failure analysis of PLA samples}

The failure surfaces of specimens made of PLA which were experimentally tested under 3PB may be observed in Figure 12. In the honeycomb arrangement $\mathrm{Hr}_{-} 0$, the failure seems to start at triple junctions, while for Hr_45 disruption of the sample starts at the triple junctions and also at the struts that make $45^{\circ}$ with the axis $X_{1}$. Sample Hr_90 fails at struts oriented at $90^{\circ}$ of the axis $X_{1}$. A $\overline{1}$ l lotus structures break at the middle of the struts, independently of the orientation angle. The hexagonal honeycomb with Plateau borders show distinct initial failure zones for different orientation angles. Specimen Pt_0 starts to break at zones close to the plateau border, whereas Pt_45 and Pt_90 initiate failure at the middle of the struts making angles, respectively, of $45^{\circ}$ and $90^{\circ}$ with axis $X_{1}$.

The failure zones of Figure 12 are in straight correlation with the regions where the von Mises stress attains higher values, as illustrated in Figure 11.

\section{Discussion}

New periodic cellular configurations have significant potential to be used as functional structures at the core of sandwich panels. Lately, intensive research has been conducted pursuing the challenge of tailoring new structures with high strength, stiffness and absorbed energy combined with low weight. In fact, several novel structures with complex geometries have been proposed and compared with the most conventional hexagonal honeycomb. The experimental study of samples with complex geometric features was only made possible with the development of additive manufacturing processes, as there are some limitations for such production in the conventional procedures. 


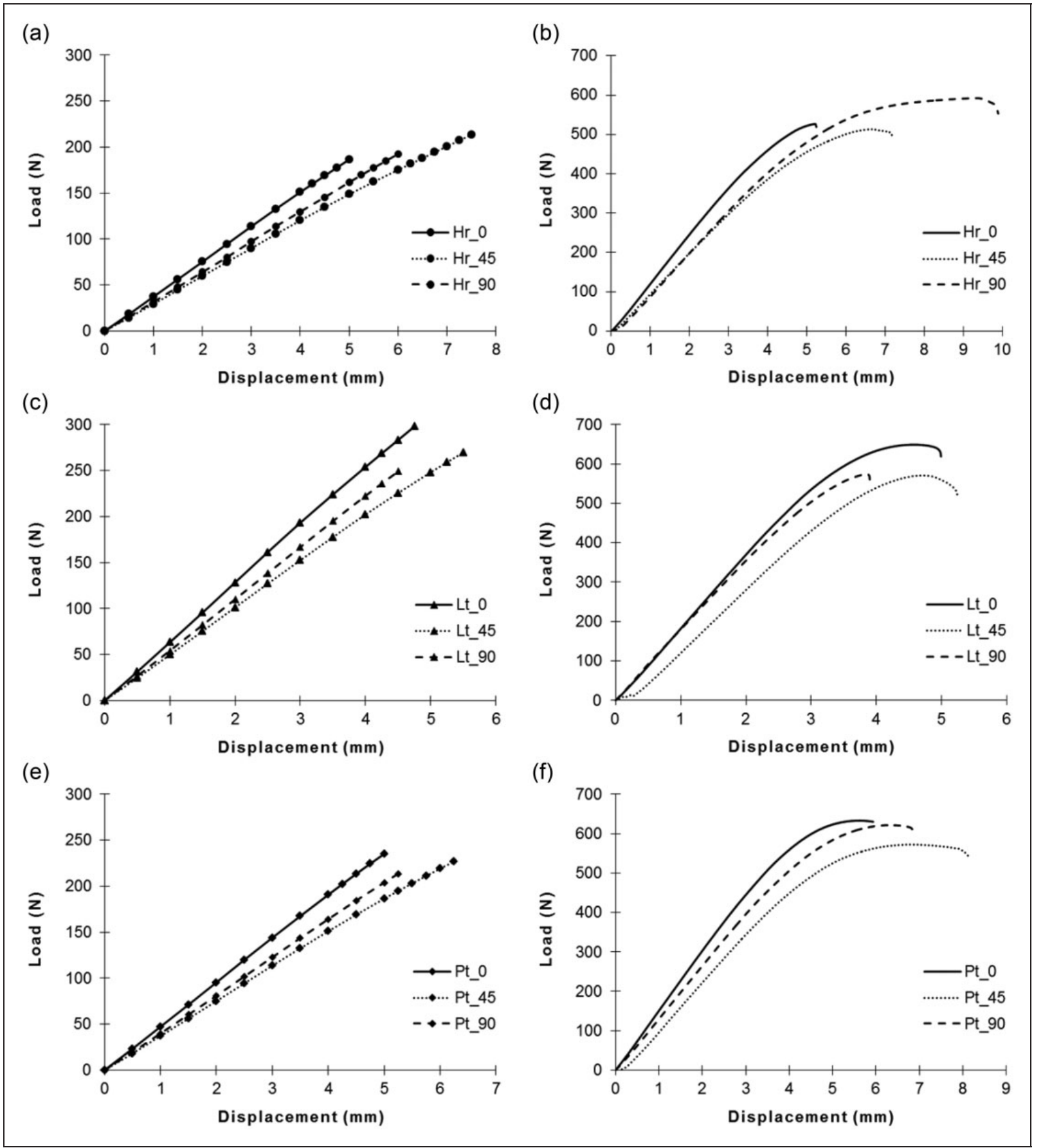

Figure 10. Load-displacement curves for PLA specimens for the different configurations: (a)-(b) Hr, (c)-(d) Lt, (e)-(f) Pt. Numerical curves (a), (c), (e) and experimental curves until fracture (b), (d), (f).

The present work studied the flexural behavior of two arrangements, lotus (Lt) and hexagonal honeycomb with Plateau borders (Pt) and compared them with the conventional regular hexagonal honeycomb $(\mathrm{Hr})$. Three different in-plane orientations were evaluated. Three groups of samples were obtained by three distinct manufacturing procedures, for two aluminum alloys and a polymer, PLA.

It is well known that the mechanical properties of cellular materials depend, among other factors, on the material properties of its constituents, topology, and the relative density. ${ }^{2}$ However, in the present work, the relative density was kept unchanged for each configuration.

The materials chosen were aluminum and PLA, since the most used core material of the sandwich panels is indeed aluminum, although the uses of polymeric and natural base materials have become appealing. ${ }^{51}$ From the analysis of the data obtained in the present work, the two aluminum alloys and the polymer PLA provided the same type of load-displacement responses, apart from the values obtained.

In fact, the qualitative shape of the load-displacement curves was unaffected by changing the topology 


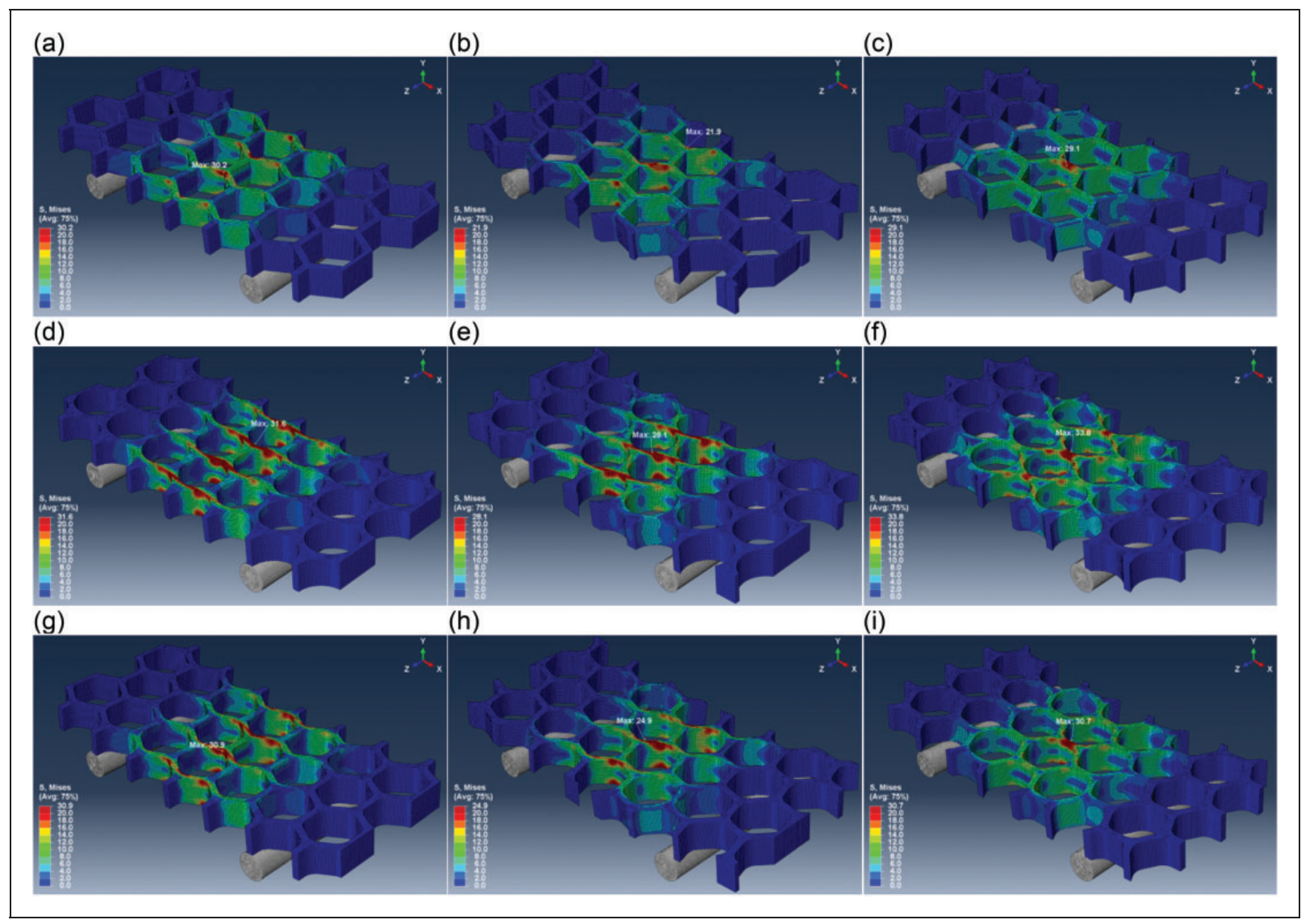

Figure II. Finite element analysis of stresses (von Mises stress (MPa)), after bending tests of honeycomb, lotus, and plateau configurations made of PLA until a displacement of $2.5 \mathrm{~mm}$. (a) Hr_0, (b) Hr_45, (c) Hr_90, (d) Lt_0, (e) Lt_45, (f) Lt_90, (g) Pt_0, (h) Pt_45, (i) Pt_90.

Table 5. FE and experimental results for bending tests of PLA samples: maximum von Mises stress $\sigma_{\max }$, stiffness $K$, and absorbed energy $E_{a}$, (scaled with the relative density, $\bar{\rho}$ ) until $d l=2.5 \mathrm{~mm}$.

\begin{tabular}{|c|c|c|c|c|c|c|}
\hline \multirow[b]{2}{*}{ Model } & \multirow[b]{2}{*}{$\bar{\rho}$} & \multicolumn{3}{|l|}{ Finite elements } & \multicolumn{2}{|l|}{ Experimental } \\
\hline & & $\bar{\sigma}_{\max } / \bar{\rho}(\mathrm{MPa})$ & $K / \bar{\rho}(\mathrm{N} / \mathrm{mm})$ & $E_{a} / \bar{\rho}(J)$ & $\mathrm{K} / \bar{\rho}(\mathrm{N} / \mathrm{mm})$ & $E_{a} / \bar{\rho}(\mathrm{J})$ \\
\hline $\mathrm{Hr} \_0$ & 0.223 & $1.35 \times 10^{2}$ & $1.70 \times 10^{2}$ & 0.526 & $5.64 \times 10^{2} \pm 26.1$ & $1.70 \pm 0.02$ \\
\hline $\mathrm{Hr}_{-} 45$ & 0.224 & $9.77 \times 10^{1}$ & $1.35 \times 10^{2}$ & 0.414 & $4.66 \times 10^{2} \pm 14.2$ & $1.34 \pm 0.07$ \\
\hline Hr_90 & 0.222 & $1.31 \times 10^{2}$ & $1.45 \times 10^{2}$ & 0.448 & $4.94 \times 10^{2} \pm 7.3$ & $1.32 \pm 0.03$ \\
\hline Lt_o & 0.285 & $1.11 \times 10^{2}$ & $2.24 \times 10^{2}$ & 0.701 & $6.60 \times 10^{2} \pm 9.7$ & $2.01 \pm 0.16$ \\
\hline Lt_45 & 0.286 & $9.82 \times 10^{1}$ & $1.79 \times 10^{2}$ & 0.550 & $5.61 \times 10^{2} \pm 13.4$ & $\mathrm{I} .43 \pm 0.03$ \\
\hline Lt_90 & 0.284 & $1.19 \times 10^{2}$ & $1.97 \times 10^{2}$ & 0.602 & $6.22 \times 10^{2} \pm 18.9$ & $1.96 \pm 0.02$ \\
\hline Pt_0 & 0.243 & $1.27 \times 10^{2}$ & $1.98 \times 10^{2}$ & 0.612 & $6.28 \times 10^{2} \pm 19.1$ & $1.94 \pm 0.07$ \\
\hline Pt_45 & 0.244 & $1.02 \times 10^{2}$ & $1.56 \times 10^{2}$ & 0.478 & $5.18 \times 10^{2} \pm 5.8$ & $1.33 \pm 0.15$ \\
\hline Pt_90 & 0.242 & $1.27 \times 10^{2}$ & $1.70 \times 10^{2}$ & 0.520 & $5.56 \times 10^{2} \pm 16.7$ & $1.69 \pm 0.12$ \\
\hline
\end{tabular}

of the cellular material. The curves are formed by an initial linear part followed by a nonlinear region, which may be associated with the onset of plastic deformation of the wall material, as well as the collapse of some cell walls. One may expect that in some elements, the stress may be higher than the yield stresses which gives rise to local plastic deformation and collapse.

Previous research has shown that the topology has an important influence on the properties of the cellular structure. ${ }^{7}$ The effect of the topology on the bending behavior was examined experimentally and numerically, showing that the lotus structure may be competitive in comparison with hexagonal honeycomb. ${ }^{7}$

In the present study with aluminum-A, aluminum$\mathrm{S}$, and PLA, among the three structures, the lotus structure, Lt, exhibited the largest flexural stiffness and absorbed energy, both in experiments and numerical tests, for the three in-plane orientations. 


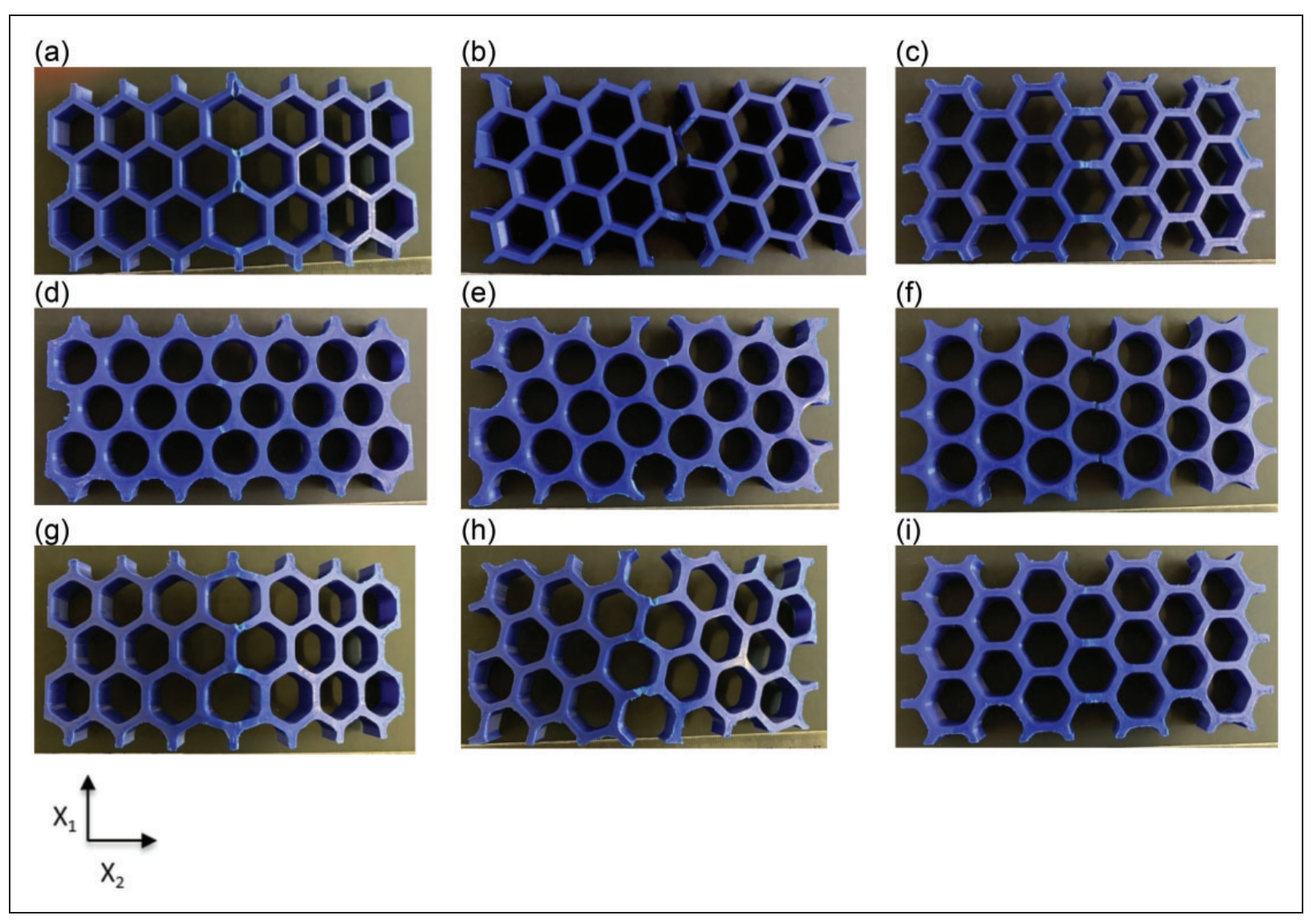

Figure 12. PLA samples after 3PB tests: (a) Hr_0, (b) Hr_45, (c) Hr_90, (d) Lt_0, (e) Lt_45, (f) Lt_90, (g) Pt_0, (h) Pt_45, (i) Pt_90.

A tendency of the hexagonal honeycomb to achieve higher strength, than the structures Lt and Pt, was detected.

The mechanical properties of these three structures, Hr, Lt, and Pt would derive, from a theoretical approach, from the distribution of material within the structure. The deformation of a hexagonal honeycomb structure occurs with a high level of stress concentration at the triple joints, whereas the lotus configuration may be regarded as a prismatic porous solid for which the deformation occurs by necking at the vertical walls. ${ }^{40}$ In turn, the plateau arrangement differs, in that it shows an accumulation of material at the vertices, i.e. at the Plateau borders. $^{40}$ Theoretically, one would expect that the lotus arrangement would reveal the highest stiffness followed by plateau and hexagonal honeycomb arrangements.

The compression of the $\mathrm{Hr}$, Lt, and Pt structures also designed with angles of $0^{\circ}, 90^{\circ}$, and $45^{\circ}$ with the axis $X_{1}$, taken into account by Araújo et al., ${ }^{39}$ enabled to establish that the deformation of the arrangements was dependent on the orientation. The higher loads were obtained in planes with $0^{\circ}$, followed by the orientations $90^{\circ}$ and $45^{\circ}$. Moreover, in the three orientation angles, both the strength and the stiffness were larger in the lotus configurations, followed by the plateau and honeycomb arrangements. ${ }^{39}$
However, the compression deformation should not be directly compared with the bending behavior. The flexural performance of the $\mathrm{Hr}$, Lt, and Pt structures with orientation angles of $0^{\circ}, 90^{\circ}$, and $45^{\circ}$ with the axis $X_{1}$, which was undertaken in the current work, with aluminum-S and PLA, shows that angle $0^{\circ}$ provides higher stiffness and absorbed energy, followed by the angles $90^{\circ}$ and $45^{\circ}$. There is a trend for the strength to be almost the same for $0^{\circ}$ and $90^{\circ}$, but having higher values than the orientation angle of $45^{\circ}$. In short, the Lt_0 configuration has shown superior results than the other structures with distinct angles.

Samples from aluminum-A and PLA were produced by additive manufacturing, respectively by SLM and material extrusion, while samples from aluminum-S were produced by machining, which is a subtractive manufacturing process. Although additive manufacturing techniques are gaining attentions due to their advantages, such as lesser waste of material, ${ }^{43}$ the disadvantage of having an anisotropic behavior has to be considered. ${ }^{18}$

The experimental load-displacement curves, obtained with aluminum-A samples, present a very good consistence with the numerically simulated curves, which demonstrate the effectiveness of the FE models. This good agreement was reached while assuming that the material was isotropic. In effect, 
when producing parts using SLM technology, for which the powder is dispersed on a surface, exposed to a selected fusion, one may conclude that anisotropy does not exist, with no specific crystallization direction. However, the SLM process will inevitably introduce randomly distributed imperfections, which will be responsible for deviations towards the relative perfect numerical model. ${ }^{35}$ Also, deviations from experiments and simulations may derive from the stress-strain relation used which was obtained from uniaxial tension tests. However, in bending tests, the struts will be subjected to tension, compression, or bending, being this complex stress state not fully captured in a simple elastic-plastic material behavior model. ${ }^{43}$ Moreover, the deposition conditions allowing the production of standard test coupons may differ from the ones present when producing the desired structures.

For the aluminum-S models, the cellular structures have been machined from an isotropic plate, and one may assume that the cell wall material has an isotropic behavior. This is reflected in a strong correlation between the numerical models and the experimental results.

A deviation between the experimental and the numerical simulations was detected in PLA samples produced by FFF. The parts produced by this process are formed by an external contour line that surrounds an inside zone denoted by infill. The contour and the infill zones have different properties, with the contour lines having high stiffness and strength. ${ }^{7}$ If the struts are thin, they may be formed only by the contour lines and possess no infill material, which give rise to compact struts. ${ }^{39}$

It should be noted that the tensile test specimens, used to obtain the Young's modulus were dominated by the infill zones. Since infill has lower stiffness and strength than the contour lines, the value of $E$ used in modeling, should be lower than the one of the honeycomb cell walls, where the contour zone make up much of the structure rather than infill.

An observation of the failed PLA samples allows inferring that failure starts to occur at the zones that exhibited high values of the maximum von Mises stress. Stress distribution shows that the stress is highly concentrated in the areas near the loading points where local failure will take place.

Failure starting points depend on the geometry and on the in-plane angle, with the exception of the lotus geometry. Lotus structure was found to fail always at the middle points of the struts.

The failure of the hexagonal honeycomb with orientation angle of $0^{\circ}$ was found to occur at the triple junctions, which are sharp edges, and consequently are stress concentration spots. This is in accordance with previous studies. ${ }^{7}$ For the hexagonal honeycomb and the angles $45^{\circ}$ and $90^{\circ}$, the failure at the struts is observed. The hexagonal honeycomb with Plateau borders exhibits failure near the plateau border for samples with angle orientation of $0^{\circ}$, but the breakage of the middle of the struts was detected for orientation angles of $45^{\circ}$ and $90^{\circ}$.

\section{Conclusions}

In this work, metallic and polymeric honeycomb structures with different configurations such as hexagonal honeycomb, lotus and hexagonal honeycomb with Plateau borders, with $0^{\circ}, 45^{\circ}$, and $90^{\circ}$ orientations were manufactured. Aluminum-A samples were fabricated by selective laser melting, while aluminum$\mathrm{S}$ specimens were obtained by machining. Specimens of PLA were manufactured by FFF.

Experiments and numerical modeling of $3 \mathrm{~PB}$ tests were conducted to evaluate the mechanical properties of the structures. For the metallic samples, a very good correlation between numerical and experimental results was found, whereas in the case of the polymeric samples the match is not as close, which is justified by the manufacturing procedure. Nevertheless, the trends in the case of different geometries can still be established.

Among the three orientations analyzed, either from numerical or experimental results, the structures with $0^{\circ}$ orientation are those that have the highest stiffness and absorbed energy. Also, in general, for the same configuration, $45^{\circ}$ orientation structures show the lowest stiffness and the lowest energy absorbed.

For the same orientation, Lt arrangements show higher stiffness and absorb higher energy than $\mathrm{Pt}$ structures, while there is a tendency for $\mathrm{Hr}$ structures to exhibit higher strength.

Since the Lt configuration with $0^{\circ}$ orientation achieves the highest stiffness and absorbed energy among the structures analyzed, it may be an alternative to the more conventional hexagonal honeycomb in applications where these two properties are required.

In most cases failure occurs due to localized stress concentration. In fact, the failure zones were found to be in accordance with the model predictions for the higher values of the maximum von Mises stress.

The current experimental and numerical results indicate that designed configurations of the cores of sandwich panels can be used to tailor the bending properties of the structures. These findings provide new insights into the mechanical response of panel cores, which may benefit a wide range of industrial applications.

\section{Highlights}

- Honeycomb structures based on lotus, hexagonal with Plateau borders and regular hexagonal structures were designed.

- Samples of aluminum and PLA were obtained by additive manufacturing and subtractive processes. 
- Three in-plane orientations were tested through 3PB tests.

- Experimental tests and numerical simulations were undertaken.

- The mechanical response and failure behavior under 3PB were analyzed.

- The Lotus configuration with $0^{\circ}$ orientation achieves the highest stiffness and absorbed energy.

\section{Acknowledgments}

A special thank is due to Francisco Pato and the company Viagop (Sociedade de Engenharia e Imobiliária, Lisbon) that gently provided the aluminum-S samples.

\section{Declaration of conflicting interests}

The author(s) declared no potential conflicts of interest with respect to the research, authorship, and/or publication of this article.

\section{Funding}

The author(s) disclosed receipt of the following financial support for the research, authorship, and/or publication of this article: This work was supported by FCT, through IDMEC, under LAETA, Project UIDB/50022/2020.

\section{ORCID iDs}

A Miranda (D) https://orcid.org/0000-0003-0378-4675

MF Vaz (D) https://orcid.org/0000-0003-1629-523X

AM Deus (DD https://orcid.org/0000-0002-0451-6245

\section{References}

1. Bitzer T. Honeycomb technology: materials, design, manufacturing, applications and testing. New York: Springer, 1997.

2. Gibson LJ and Ashby M. Cellular solids, structure and properties. Cambridge: Cambridge University Press, 1997.

3. Schaedler TA and Carter WB. Architected cellular materials. Annu Rev Mater Res 2016; 46: 187-210.

4. Vinson JR. The behavior of sandwich structures of isotropic and composite materials. Boca Raton, FL: CRC Press, 1999.

5. Zhu F, Lu G, Ruan D, et al. Plastic deformation, failure and energy absorption of sandwich structures with metallic cellular cores. Int J Prot Struct 2010; 1: 507-541.

6. Birman V and Kardomateas GA. Review of current trends in research and applications of sandwich structures. Compos Part B Eng 2018; 142: 221-240.

7. Araújo H, Leite M, Ribeiro A, et al. The effect of geometry on the flexural properties of cellular core structures. Proc IMechE, Part L: J Materials: Design and Applications 2019; 233: 338.

8. Allen HG. Analysis and design of structural sandwich panels: the commonwealth and international library: structures and solid body mechanics. New York: Elsevier, 2013.

9. Li T and Wang L. Bending behavior of sandwich composite structures with tunable 3D-printed core materials. Compos Struct 2017; 175: 46-57.
10. Wang Z, Tian H, Lu Z, et al. High-speed axial impact of aluminum honeycomb - experiments and simulations. Compos Part B Eng 2014; 56: 1-8.

11. Kumar SS, Rao MS, Balasundar I, et al. Compressive behaviour of a nickel superalloy Superni 263 honeycomb sandwich panel. $J$ Sandw Struct Mater 2020; 22: 1426-1449.

12. Rupp P, Elsner P and Weidenmann KA. Failure mode maps for four-point-bending of hybrid sandwich structures with carbon fiber reinforced plastic face sheets and aluminum foam cores manufactured by a polyurethane spraying process. J Sandw Struct Mater 2019; 21 : 2654-2679.

13. Wadley H. Fabrication and structural performance of periodic cellular metal sandwich structures. Compos $S c i$ Technol 2003; 63: 2331-2343.

14. Arunkumar M, Pitchaimani J and Gangadharan K. Bending and free vibration analysis of foam-filled truss core sandwich panel. J Sandw Struct Mater 2018; 20: 617-638.

15. Chu S, Gao L, Xiao M, et al. Design of sandwich panels with truss cores using explicit topology optimization. Compos Struct 2019; 210: 892-905.

16. Helou M and Kara S. Design, analysis and manufacturing of lattice structures: an overview. Int $J$ Comput Integr Manuf 2018; 31: 243-261.

17. Monteiro J, Sardinha M, Alves F, et al. Evaluation of the effect of core lattice topology on the properties of sandwich panels produced by additive manufacturing. Proc IMechE, Part L: J Materials: Design and Applications 2020. DOI: 146442072095801.

18. Fiedler $\mathrm{T}$ and Öchsner A. Experimental analysis of the flexural properties of sandwich panels with cellular core materials. Materwiss Werksttech 2008; 39: 121-124.

19. Gdoutos EE, Daniel IM, Wang K-A, et al. Nonlinear behavior of composite sandwich beams in three-point bending. Exp Mech 2001; 41: 182-189.

20. Zarei Mahmoudabadi M and Sadighi M. Experimental investigation on the energy absorption characteristics of honeycomb sandwich panels under quasi-static punch loading. Aerosp Sci Technol 2019; 88: 273-286.

21. Palomba G, Crupi V and Epasto G. Collapse modes of aluminium honeycomb sandwich structures under fatigue bending loading. Thin-Walled Struct 2019; 145: 106363.

22. Lan X, Feng S, Huang Q, et al. A comparative study of blast resistance of cylindrical sandwich panels with aluminum foam and auxetic honeycomb cores. Aerosp Sci Technol 2019; 87: 37-47.

23. Panda B, Leite M, Biswal BB, et al. Experimental and numerical modelling of mechanical properties of $3 \mathrm{D}$ printed honeycomb structures. Measurement 2018; 116: 495-506.

24. Burton WS and Noor AK. Assessment of continuum models for sandwich panel honeycomb cores. Comput Methods Appl Mech Eng 1997; 145: 341-360.

25. Ingrole A, Hao A and Liang R. Design and modeling of auxetic and hybrid honeycomb structures for in-plane property enhancement. Mater Des 2017; 117: 72-83.

26. Surjadi JU, Gao L, Du H, et al. Mechanical metamaterials and their engineering applications. Adv Eng Mater 2019; 21: 1800864.

27. Zhang Z, Zhang Q, Zhang D, et al. Enhanced mechanical performance of brazed sandwich panels with high 
density square honeycomb-corrugation hybrid cores. Thin-Walled Struct 2020; 151: 106757.

28. Xu J, Wu Y, Wang L, et al. Compressive properties of hollow lattice truss reinforced honeycombs (Honeytubes) by additive manufacturing: patterning and tube alignment effects. Mater Des 2018; 156: 446-457.

29. Du Y, Li H, Luo Z, et al. Topological design optimization of lattice structures to maximize shear stiffness. Adv Eng Softw 2017; 112: 211-221.

30. Qi G, Chen Y-L, Richert P, et al. A hybrid joining insert for sandwich panels with pyramidal lattice truss cores. Compos Struct 2020; 241: 112123.

31. Yan C, Hao L, Hussein A, et al. Evaluation of lightweight AlSi10Mg periodic cellular lattice structures fabricated via direct metal laser sintering. $J$ Mater Process Technol 2014; 214: 856-864.

32. Li Y, Jahr H, Pavanram P, et al. Additively manufactured functionally graded biodegradable porous iron. Acta Biomater 2019; 96: 646-661.

33. Habib FN, Iovenitti P, Masood SH, et al. Fabrication of polymeric lattice structures for optimum energy absorption using Multi Jet Fusion technology. Mater Des 2018; 155: 86-98.

34. Ullah I, Brandt $M$ and Feih S. Failure and energy absorption characteristics of advanced 3D truss core structures. Mater Des 2016; 92: 937-948.

35. Wei K, Yang Q, Yang X, et al. Mechanical analysis and modeling of metallic lattice sandwich additively fabricated by selective laser melting. Thin-Walled Struct 2020; 146: 106189.

36. Lei H-Y, Li J-R, Xu Z-J, et al. Parametric design of Voronoi-based lattice porous structures. Mater Des 2020; 191: 108607.

37. Leary M, Mazur M, Williams H, et al. Inconel 625 lattice structures manufactured by selective laser melting (SLM): mechanical properties, deformation and failure modes. Mater Des 2018; 157: 179-199.

38. Liu Y, Dong Z, Ge J, et al. Stiffness design of a multilayer arbitrary BCC lattice structure with face sheets. Compos Struct 2019; 230: 111485.

39. Araújo H, Leite M, Ribeiro A, et al. Investigating the contribution of geometry on the failure of cellular core structures obtained by additive manufacturing. Frat Ed Integrità Strutt 2019; 13: 478-486.
40. Ronan W, Deshpande VS and Fleck NA. The tensile ductility of cellular solids: the role of imperfections. Int $J$ Solids Struct 2016; 102-103: 200-213.

41. Yang L, Hsu K, Baughman B, et al. Additive manufacturing of metals: the technology, materials, design and production. New York: Springer, 2017.

42. Croccolo D, De Agostinis M and Olmi G. Experimental characterization and analytical modelling of the mechanical behaviour of fused deposition processed parts made of ABS-M30. Comput Mater Sci 2013; 79: 506-518.

43. Rashed MG, Ashraf M, Mines RAW, et al. Metallic microlattice materials: a current state of the art on manufacturing, mechanical properties and applications. Mater Des 2016; 95: 518-533.

44. Rehme O. Cellular design for laser freeform fabrication. Göttingen: Cuvillier, 2010.

45. Crump S. Apparatus and method for creating threedimensional objects. US Patent 5,121,329 15, 1992.

46. Turner BN and Gold SA. A review of melt extrusion additive manufacturing processes: I. Process design and modeling. Rapid Prototyp J 2014; 20: 192-204.

47. Rybachuk M, Alice Mauger C, Fiedler T, et al. Anisotropic mechanical properties of fused deposition modeled parts fabricated by using acrylonitrile butadiene styrene polymer. J Polym Eng 2017; 37: 699-706.

48. Elmrabet N and Siegkas P. Dimensional considerations on the mechanical properties of $3 \mathrm{D}$ printed polymer parts. Polym Test 2020; 90: 106656.

49. Farah S, Anderson DG and Langer R. Physical and mechanical properties of PLA, and their functions in widespread applications - A comprehensive review. Adv Drug Deliv Rev 2016; 107: 367-392.

50. Fernandes J, Deus AM, Reis L, et al. Study of the influence of 3D printing parameters on the mechanical properties of PLA. In: Chua CK, Yeong WY, Tan MJ and Liu E (eds) Proceedings of the international conference on progress in additive manufacturing, Singapore, 2018.

51. Stocchi A, Colabella L, Cisilino A, et al. Manufacturing and testing of a sandwich panel honeycomb core reinforced with natural-fiber fabrics. Mater Des 2014; 55: 394-403. 